\title{
El uso del anonimato en los élenchoi del Protágoras y Gorgias*
}

\author{
Rodolfo Arbe \\ Universidad de Buenos Aires
}

\begin{abstract}
Resumen: Este trabajo forma parte de los estudios sobre el anonimato en Platón. La cuestión del anonimato no se reduce a la desaparición del autor detrás de las palabras de los dialogantes, sino que incluye en su tematización otras aristas, dentro de las cuales puede incluirse la figura del interlocutor anónimo. En este trabajo nos ocuparemos de analizar la participación de este interlocutor anónimo en los élenchoi del Protágoras y Gorgias, con vistas a determinar la función de su incorporación en esos diálogos. En los casos analizados, el interlocutor anónimo toma la palabra, por medio del pronombre indefinido "alguien" (tis), la figura de la mayoría (hoi polloi), o bajo la máscara de alguna profesión (el médico, el banquero, etcétera).
\end{abstract}

Palabras clave: anonimato; élenchos; Platón; refutación; anónimo

\begin{abstract}
The Anonymity in the Elenchoi of Protagoras and Gorgias". This paper is part of the studies on anonymity in Plato. The question of anonymity is not limited to the disappearance of the author behind the words of the characters, but includes other aspects, within which we may include the figure of the anonymous interlocutor. In this paper we will analyze the intervention of this anonymous interlocutor in the elenchoi of Protagoras and Gorgias, for the purpose of determining the role of their inclusion in these dialogues. In the analyzed cases the anonymous interlocutor takes the word, by means of the indefinite pronoun "someone" (tis), the figure of the majority (hoi polloi), or under the mask of some profession (doctor, banker, etc.).
\end{abstract}

Keywords: anonymity; élenchos; Plato; refutation; anonymous

* Agradezco a los evaluadores anónimos de Areté por sus minuciosas observaciones, que permitieron el mejoramiento del trabajo. 


\section{Introducción}

En este trabajo nos ocuparemos de analizar la figura del interlocutor anónimo en el marco de los procesos refutativos socráticos llevados a cabo en los diálogos Protágoras y Gorgias. A lo largo del artículo analizaremos cuáles son los beneficios de introducir un personaje sin nombre. Para ver la modalidad en la que se presenta el interlocutor anónimo, comencemos por algunas de sus intervenciones en la introducción del Protágoras ${ }^{1}$ :

(1) "Si entonces alguien (tis), al hallarnos tan decididamente afanosos en esto, nos preguntara: 'Decidme, Sócrates e Hipócrates, ¿qué opinión tenéis de lo que es Protágoras al darle vuestro dinero?', ¿qué le responderiamos?..." (Prot. 311d6-8)2.

(2) "Si luego alguno (tis) te preguntara también esto: ‘¿Y tú, en qué tienes intención de convertirte al acudir a Protágoras" (Prot. 311e6-a1).

(3) "Luego si alguien (tis) nos preguntara: '¿De qué cosas sabias son conocedores los pintores?', le contestariamos, sin duda, que de las que respectan a la ejecución de las imágenes y demás cosas por el estilo. Pero si alguno nos preguntara: '¿El sofista en cuál de las cosas sabias es entendido?', ¿qué le responderiamos? ¿De qué actividad es maestro?" (Prot. 312d1-d5).

En estos casos el anónimo es invocado por medio del pronombre indefinido (tis) que aparece en la prótasis de períodos potenciales ${ }^{3}$. Esos períodos introducen preguntas conocidas como "interrogaciones ficticias", por medio de las cuales, en ciertas ocasiones, un interlocutor anónimo toma la palabra y se convierte en enunciador a través de la modalidad del "discuro directo" (direct speech). Las interrogaciones ficticias, según Angela Longo, tienen cuatro

2361 Al comienzo de la conversación entre Sócrates e Hipócrates, el interlocutor anónimo aparece en seis oportunidades, siempre en actitud interrogativa. Citamos solo tres de ellas porque expresan cabalmente la funcionalidad que las animan, las otras pueden consultarse en: $311 \mathrm{~b} 8-\mathrm{c} 1 ; 311 \mathrm{c} 5-7$; 312a1-2.

2 En cuanto al Protágoras, seguimos la traducción de García Gual para Gredos. Cf. Platón, Dialogos I: Apología, Critón, Eutifrón, Ion, Lisis, Cármides, Hipias Menor, Hipias Mayor, Laques, Protágoras, Garcia Gual, C. (trad.), Madrid: Gredos, 2000.

3 En los pasajes analizados nos encontramos con períodos potenciales compuestos en la prótasis por un verbo en optativo y, en la apódosis, el verbo en optativo está acompañado por la partícula "àn". 
funciones específicas dentro de los diálogos, y tres de ellas contemplan el caso del personaje sin nombre. A fin de analizar la figura del anonimato dentro del élenchos, nos va a servir de ayuda retomar la clasificación de las funciones propuesta por Longo ${ }^{4}$ :

(1) Función paradigmática: Las interrogaciones ficticias y el recurso del anónimo le permiten a Sócrates ejemplificar el tipo de respuestas que espera de su interlocutor. Por medio del anónimo (tis), Sócrates se pone como modelo a seguir en las respuestas, y su interlocutor es invitado a imitar la manera en que el filósofo respondió.

(2) Implicación indirecta del interlocutor: Una interrogación ficticia puede tener como función implicar indirectamente al interlocutor. Esto ocurre, generalmente, en las conversaciones con sofistas (Protágoras, Gorgias o Hipias), posibilitándole a Sócrates disminuir la tensión interna del diálogo.

(3) Adquisición de ciertas premisas: Esta función permite que ciertas premisas sean acordadas por el interlocutor. Sócrates se sirve del anonimato para alternar el rol de interrogador con el de interrogado, y así controlar las preguntas y las respuestas. Recurrir a un interlocutor anónimo le permite responder en nombre del otro y lograr el asentimiento de algunas premisas.

El objetivo de este trabajo consiste en identificar estas funciones en los élenchoi del Protágoras y Gorgias para ver de qué manera se implican mutuamente al servicio de la refutación. Esto nos va a permitir argumentar a favor de la inclusión del recurso del "interlocutor anónimo" dentro de lo que Beversluis llama "psychologically manipulative tactics", es decir, tácticas psicológicas persuasivas, que conducen a los interlocutores a la refutación ${ }^{5}$.

\section{El interlocutor anónimo dentro del primer élenchos del Protágoras}

El encuentro entre Sócrates y Protágoras en el diálogo homónimo representa un cruce de disciplinas que se organizan alrededor de un tema común, la virtud (areté), sobre el cual la filosofia y la sofística tienen perspectivas diferentes. El tema central de la discusión surge cuando se presenta a los sofistas

\footnotetext{
4 Llevo a cabo un resumen de las funciones teniendo en cuenta, exclusivamente, aquellas que incluyen al personaje anónimo. $C f$. Longo, A., $L^{\prime}$ art du questionnement et les interrogations fictives chez Platon, Lernould, A. (trad.), Milán: Mimesis Edizioni, 2007, pp. 153-157.

5 Cf. Beversluis, J., Cross-examining Socrates, Cambridge: Cambridge University Press, 2000, p. 46.
} 
como maestros capaces de mejorar el alma de aquellos interesados en recibir sus lecciones. A partir de ahí, Sócrates introduce la problemática sobre la posibilidad de enseñar la virtud (areté). Para ello, será necesario analizar la tesis del sofista, quien concibe la virtud como una cierta unidad cuyas partes son: la sabiduría, la justicia y la piedad (Prot. 329c6-8), agregando poco después la valentía (330a1), cada parte distinta de la otra (Prot. 330a3-4). Precisamente esta última característica, la diferencia entre las partes, será objeto del primer proceso refutativo, cuyo objetivo consistirá en reducir al absurdo la posición del sofista y, de ese modo, sumar razones a favor del enunciado socrático que afirma la unidad de la virtud y la semejanza de sus partes (329c6-d1) ${ }^{6}$. La clave para lograr esto será tomar dos de las virtudes (la justicia y la piedad), y asignarles a cada parte una opción de la dicotomía "justo-injusto" y "píoimpío", respectivamente, de modo tal que, si las virtudes son diferentes entre sí, entonces cada una de ellas no podrá tener la propiedad que le fue adjudicada a la otra. Para que funcione la estrategia del filósofo, es necesario que la dicotomía sea entendida como un par de "contradictorios" y no de contrarios?. A continuación, veremos de qué manera el interlocutor anónimo se pone al servicio de la argumentación:

(4) “-¿Qué entonces? Si alguien (tis) nos preguntara a ti y a mí: ‘Protágoras y Sócrates, decidme, esa realidad que nombrasteis hace un momento, la justicia, ella misma es justa o injusta?', yo le respondería que justa. ¿Y tú qué voto depositarías? ¿El mismo que yo, o diferente? - El mismo, dijo.

-Por consiguiente, la justicia es semejante al ser justo (hoion dikaion einai), diría yo en respuesta al interrogador. ¿Es que tú no?” (Prot. $330 c 2-d 1)$.

6 La tesis socrática acerca de la unidad de la virtud ha generado varias interpretaciones. El debate que más repercusión tuvo fue entre los defensores de la unidad de la virtud en términos de identidad, cuyo máximo exponente es Terry Penner y, por otro lado, la postura de Gregory Vlastos, quien sostuvo que las virtudes no son idénticas para Sócrates, sino que están relacionadas "bicondicionalmente". Cf. Penner, T., "The Unity of Virtue", en: Philosophical Review, v. LXXXIII (1973), pp. 35-68; Vlastos, G., "The Unity of the Virtues in the Protagoras", en Vlastos, G., Platonic Studies, Princeton: Princeton University Press, 1981 (2 ed.), pp. 418-423. Vale la pena consultar los trabajos al respecto de: Brickhouse, C. y N. Smith, "Socrates and the Unity of the Virtues", en: The Journal of Ethics, v. I, n. 4 (1997), pp. 311-324; Devereux, D., "The Unity of the Virtues", en: The Philosophical Review, v. CII (1993), pp. 765-789.

7 El lingüista John Lyons lleva a cabo una buena caracterización de los opuestos léxicos en su libro Semantics, distinguiendo entre opuestos contrarios (frío-calor) y contradictorios (hombremujer). En el caso de los contradictorios, o se es una opción o la otra. Cf. Lyons, J., Semantics, Londres: Cambridge University Press, 1993, pp. 270-290. 
La primera participación del interlocutor anónimo introduce una proposición que ha tenido una gran repercusión en los estudios platónicos: "la justicia es justa", retomada a propósito de la problemática sobre la auto-predicación de las Ideas ${ }^{8}$. A los fines de este trabajo, solo nos limitamos a hacer mención de que es el interlocutor anónimo quien introduce el par "justo-injusto" como alternativas exhaustivas y contradictorias correspondientes a la justicia (dikaiosyne). Como bien advierte Taylor en su comentario sobre el Protágoras, la presentación de este par en 330c5 como opuestos contradictorios no es ingenuo, sino que tiene motivaciones especificas dentro de la argumentación ${ }^{9}$. Por lo general, "justo e injusto" son contrarios, excepto en ciertos contextos restringidos, como por ejemplo, los procedimientos legales o las reglas de un juego, donde algo es justo o injusto sin término medio. En este argumento, la estrategia socrática será conducir al sofista a sostener, a través de la asunción de estos pares como contradictorios, que la justicia es impía, y la piedad injusta, algo que resulta incomprensible para cualquier griego. Para lograr eso, en un primer momento, Sócrates, por medio del anónimo, define a la justicia como semejante (hoion) a ser justo, o sea, "x es como ser F", que es prácticamente sinónimo de "x es F", y luego hace lo mismo con la piedad:

(5) “-Si luego, a continuación nos preguntara: ‘¿Por consiguiente también decís que la piedad existe?’, lo afirmamos, según creo. -Sí, dijo él" (Prot. 330d1-3).

(6) “ ¿YY de esa misma realidad decís que, por naturaleza, es semejante a ser impío o a ser piadoso?' Me irritaría al menos yo con la pregunta, dije, y contestaría: ‘ $¡ N o$ blasfemes, hombre! Dificilmente habria alguna otra cosa piadosa, si no fuera piadosa la propia piedad' Y tú, ¿qué? ¿No responderías así? - desde luego, dijo" (Prot. 330d5-e2).

(7) “-Si, después de eso, dijera preguntándonos: ‘¿Qué acabáis de decir? ¿Es que no os he oído bien? Me había parecido que decíais que las partes de la virtud estaban unas respecto de las otras, de tal modo que ninguna de ellas era como la otra', yo le respondería que: 'lo demás lo has oído bien, pero en cuanto crees que yo también he

\footnotetext{
8 La tesis de la autopredicación de las Ideas divide a los intérpretes entre los que conciben una verdadera autopredicación, y los que solo ven meras expresiones de autoidentidad. Dada la vasta bibliografia al respecto, para un recorrido por las diferentes posiciones vale la pena consultar el capitulo dedicado a este tema en: Di Camillo, S., Eidos. Teoria platónica de las Ideas, La Plata: Edulp, 2016.

9 Cf. Taylor, C.C.W., Notes on Plato's Protagoras, Oxford: Clarendon Press, 2002, p. 113.
} 
dicho eso, te has equivocado. Porque fue Protágoras, aquí a mi lado, el que respondió eso; yo solo preguntaba" (Prot. 330e3-331a).

Del mismo modo que pasó con la justicia, se presenta al par "pío-impío" como contradictorio, es decir, o se es pío o impío, una de las dos opciones. En (7) el interlocutor anónimo advierte la dificultad que existe en postular a los pares "justo-injusto" y "pío-impío" como contradictorios, y al mismo tiempo afirmar que la justicia es justa, y la piedad, pía. Si tenemos que la justicia y la piedad son cosas diferentes, como dijo Protágoras, entonces el razonamiento comprometería al sofista a negar que la justicia sea pía, y la piedad, justa; algo que va en contra del sentido común de la época. Por ese motivo, el interlocutor anónimo pone de manifiesto el problema que se deduce de las premisas del razonamiento asumidas hasta el momento:

(8) “-Entonces, Protágoras, qué le responderemos tras reconocerlo si nos preguntara '¿Por consiguiente, no es la piedad una cosa justa ni la justicia algo piadoso, sino algo no piadoso? ¿Y la piedad, algo no justo, sino, por consiguiente, injusto; y lo justo, impio?' Yo, personalmente, por mi cuenta, diría que la justicia es piadosa y la piedad, justa. Y en tu nombre, si me lo permites, le responderia lo mismo, que lo mismo es la justicia que la piedad o lo más semejante, y que, sobre todas las cosas, se parece la justicia a la piedad, y la piedad a la justicia. Pero mira si me prohíbes responder, o si concuerdas en opinar de ese modo" (Prot. 331a6-b8).

La conclusión a la que llega el interlocutor anónimo es que, tal como ha sido planteado el asunto, la justicia sería algo no piadoso, y la piedad algo no justo. Esto es producto de interpretar los pares de opuestos como contradictorios. Reconstruyamos el argumento, siguiendo la interpretación de Taylor, tal como la expone en su traducción del Protágoras, para ver claramente las premisas en cuestión ${ }^{10}$.

330a3 1. Cada virtud es numéricamente distinta de cualquier otra

330a4 2. Cada virtud tiene su propio poder (dúnamis).

330a4-b6 3. Ninguna virtud es semejante a otra, ni en sí misma, ni con respecto a su poder.

330c1-2 4. La justicia es algo.

$330 c 2-7$ 5. La justicia es algo justo.

${ }^{10}$ Traducción propia. Cf. Taylor, C. C. W., Notes on Plato's Protagoras, o.c., pp. 109-110. 
330c7-d1 6. La justicia es como ser justo.

330d2-5 7. La piedad es algo.

330d5-e2 8. La piedad es como ser algo pío.

331a7-8 9. La piedad no es como ser algo justo (de 3 y 5).

331 a8 10. La justicia no es como ser algo pío (de 3 y 8).

331a8-9 11. La justicia es como ser no-pío (de 10).

331 a9 12. La piedad es como ser no-justo (de 9).

331a9-b1 13. La piedad es como ser injusto (de 12).

14. La justicia es como ser impío (de 11).

331b1-3 15. Pero la justicia es pía y la piedad es justa.

331b3-6 16. Entonces, la justicia y la piedad son semejantes una con otra. ( 3 es falsa, por reductio ad absurdum)

Para que se deduzca la novena premisa: "la piedad no es como ser algo justo", es necesario que se afirme que las virtudes son diferentes entre sí, y que la justicia es algo justo. A continuación, se infiere que la piedad es como ser no-justo, o sea, injusto; para esto es necesario que los pares "justo-injusto" y "pío-impío" sean considerados como contradictorios, y no como contrarios. Ahí radica la falacia del argumento. Si tenemos en cuenta que estos pares son contradictorios, entonces, necesariamente, cada virtud será una de las dos opciones. Por lo tanto, siendo la justicia justa, la piedad sería algo injusto y, bajo el mismo razonamiento, la justicia impía.

Luego de que Sócrates ha conducido al sofista a una conclusión indeseada, Protágoras manifiesta su incomodidad ante el proceder socrático:

(9) “-No me parece, Sócrates, contestó, que sea el asunto tan sencillo, como para conceder que la justicia sea piadosa o la piedad justa, sino que me parece que algo diferente hay en esa asimilación. ¿Pero qué importa eso? Si quieres, pues, sea para nosotros la justicia piadosa y la piedad justa.

-No, ¡Por favor!, dije yo. Pues para nada necesito lo de 'si quieres' y 'si te parece', al buscar una refutación, sino solo a ti y a mí. Y digo esto de 'a ti' y 'a mí', pensando que sería la mejor manera de dar una refutación al razonamiento, si se le quitaran los 'si..." (Prot. 331b8-d1).

Protágoras le pone un límite a la conducción de Sócrates, manifestando su indiferencia frente a las respuestas conjuntas que viene dando en nombre de los dos. Evidentemente, Sócrates abusó del recurso del anonimato, y el sofista ya no se siente parte de la conversación. Frente a esta situación, el filósofo expresa la necesidad de que Protágoras se involucre en la examinación a fin 
de que se logre la refutación. Precisamente, este es uno de los ejemplos que toma Vlastos para incluir en su interpretación del élenchos la regla del "say what you believe"11, también llamado "asentimiento sincero" (sincere assent) ${ }^{12}$. El interrogado debe creer lo que asiente. Ahora bien, es importante tener en cuenta, tal como apunta Beversluis, que "afirmar P no es una condición necesaria para atribuirme la creencia de $\mathrm{P}$ "13. Puedo creer algo y no decirlo, y puedo afirmar algo y no creerlo. La relación entre la creencia y las afirmaciones es un tema que excede los limites de nuestra investigación. Por este motivo, nos basta con mencionar, al menos, algunos de los diferentes grados de asentimiento comunes en los diálogos que dejan en evidencia la complejidad de tomar una breve respuesta como una afirmación de una creencia. Siguiendo a Beversluis, las expresiones del tipo: "Ciertamente" (pánu ge), "Sí, por Zeus", "así parece" (phainétai o eoike), o el menos comprometido "yo supongo" (oimai), son distintas maneras de expresar el asentimiento que no necesariamente implican una creencia firme ${ }^{14}$. En el transcurso de una conversación el interlocutor puede asentir por mor de no interrumpir el desarrollo de una argumentación. De todos modos, este proceder tiene un limite cuando el sofista advierte que el filósofo está actuando de una manera ilegítima. Ahí es cuando Protágoras renuncia a continuar y Sócrates expresa la necesidad de que el sofista se involucre de nuevo en el razonamiento.

Nos interesa remarcar que el recurso del anonimato es una "táctica psicológica manipulativa" que probablemente afecte las creencias del interlocutor pero que, sin dudas, es determinante en el asentimiento de algunas premisas. En los pasajes citados, Sócrates, por medio del anónimo, formula preguntas y las responde en nombre de los dos, siempre con el consentimiento del sofista. Este procedimiento va teniendo influencia en las afirmaciones de Protágoras,

\footnotetext{
11 Para que el interlocutor se sienta refutado es necesario que diga realmente lo que piensa (say what you believe). Cf. Vlastos, G., "The Socratic Elenchus", en: Fine, G. (ed.), Plato 2. Ethics, Politics, Religion and the Soul, Oxford: Oxford University Press, 1999, pp. 36-63, p. 43; también: Irwin, T.H., "Say What You Believe", en: Apeiron, v. XXVI, (1993), pp. 1-16. Para una lista completa de los comentadores que avalan este requerimiento, véase: Beversluis, J., Cross-examining Socrates, p. 38 .

12 Benson utiliza la expresión "doxastic constraint" para referirse a esa restricción propuesta en el esquema de Vlastos. Según Benson, lo que demostraría el élenchos sería la inconsistencia entre un conjunto de afirmaciones. $C f$. Benson, H.H., "The Problem of the Elenchus Reconsidered", en: Prior, W. (ed.), Critical Assessment (Vol. III: Socratic Method), Nueva York: Routledge, 1987, pp. 97-118; Benson, H.H., "Problems with Socratic Method", en: Alan Scott, G. (ed.), Does Socrates have a Method? Rethinking the Elenchus in Plato`s Dialogues and Beyond, Pennsylvania: The Pennsylvania State University Press, 2002, pp.101-113.

13 Cf. Beversluis, J., Cross-examining Socrates, o.c., p. 47.

${ }^{14}$ Cf. Beversluis, J., Cross-examining Socrates, o.c., p. 45.
} 
quien en un comienzo sostuvo que las virtudes son diferentes entre sí y, luego de la participación del anónimo, el sofista manifiesta que la justicia tiene algo semejante a la piedad. ¿Hasta qué punto las creencias son tan firmes y los asentimientos tan sinceros? Veamos el pasaje que sigue para comprender mejor lo que venimos diciendo:

(10) “-Sin embargo, contestó él, se parece algo la justicia a la piedad. También, desde luego, en cierta manera se parece una cosa a la otra. Pues lo blanco, en cierto respecto, se parece a lo negro y lo duro a lo blando, y así las demás cosas que parecen ser más contrarias entre sí. Y las que hace poco deciamos tener distinta facultad y que no eran una como la otra. Así que con este procedimiento puedes probar, si quisieras, que todas son semejantes entre sí. Pero no es justo llamar semejantes a las cosas que tienen algo semejante, ni desemejantes a las cosas que tienen algo diferente, por más que lo semejante sea muy pequeño" (Prot. 331d1-e4).

Claramente, la función de "implicación indirecta del interlocutor" hizo su efecto a través de la figura del anónimo. En un primer momento, Protágoras afirmó que las virtudes eran diferentes entre sí, y ahora termina diciendo que son semejantes en algo. Para lograr este cambio de matiz en la opinión del sofista fue importante la participación del interlocutor sin nombre. Ahora bien, esta no fue la única función del anónimo, sino que también podemos afirmar que el recurso sirvió para adquirir ciertas premisas. Como hemos podido ver en la reconstrucción del argumento llevada a cabo por Taylor, por medio del anónimo se alcanzaron las premisas más importantes.

Teniendo en cuenta la estructura formal del élenchos, tal como lo describe Benson en su artículo Socratic Method, Sócrates apelaria al anónimo durante el segundo momento del élenchos, buscando obtener el asentimiento de algunas proposiciones con vistas a llevar a cabo la refutación. Para aclarar lo que estamos diciendo, veamos la estructura básica del proceso refutativo reconstruida por Benson ${ }^{15}$ :

1) Sócrates formula al interlocutor una pregunta cuya respuesta $p$ exhibe la sabiduria del interrogado, generalmente, pero no siempre, concerniente a la definición de algún concepto moral.

2) El interlocutor provee respuestas $q, r$ y $s$ a otras preguntas socráticas.

${ }^{15}$ Benson, H.H. "Socratic Method", en: Morrison, D.R. (ed.), The Cambridge Companion to Socrates, Cambridge : Cambridge University Press, 2011. 
3) Sócrates se ocupa de mostrar que estas respuestas implican la negación de la respuesta inicial.

4) Así, la conjunción: p.q.r.s es falsa.

Esta estructura guarda semejanza con la propuesta por Vlastos ("standard elenchus"), y nos permite ubicar la participación del anónimo en el momento que Sócrates se dedica a obtener respuestas de su interlocutor con vistas a mostrar, luego, su inconsistencia.

Antes de concluir esta sección nos interesa hacer una referencia al proceso refutativo que continúa sin la presencia del interlocutor anónimo. A partir de la incomodidad del sofista, Sócrates deja de recurrir al anónimo y el diálogo entre ambos sigue su curso. Ahora, el filósofo se propone examinar la diferencia entre otras partes de la virtud, me refiero a la "sensatez" (sophrosýne y la "sabiduría" (sophía). Recordemos que Protágoras sostenía que las virtudes eran diferentes entre sí. Por ese motivo, Sócrates le pregunta directamente al sofista si la insensatez es contraria a la sabiduria (332a5), y continúa construyendo ciertas polaridades entre opuestos (enantion), donde los pares "bello-feo" y "bueno-malo", serán tomados paradigmáticamente. Taylor sostiene que, en este caso, estamos en presencia de "opuestos polares"; sin embargo, remarca que, a lo largo de su obra, Platón usa el término "opuesto" (enantion) para referirse tanto a los "opuestos polares" como a los "opuestos contradictorios" 16 . Esta amplitud semántica dará lugar a que el argumento pueda considerarse inválido, debido al doble sentido de un término (falacia de equivocación). Continuando con la interpretación de Taylor, debemos tener en cuenta que la confusión entre "contrarios" y "contradictorios" habia sido introducida por el interlocutor anónimo en el élenchos anterior. Teniendo esto presente, Sócrates, sin la presencia del anónimo, continúa dialogando con Protágoras, y obtiene dos nuevas respuestas que terminan de conformar la tríada decisiva para la refutación:

$\mathrm{q}=\mathrm{La}$ insensatez es contraria de la sabiduria. (Prot. 332a5)

$\mathrm{r}=$ Cada cosa tiene un contrario (enantion). (Prot. 332d1-2) $\mathrm{s}=\mathrm{La}$ insensatez es contraria de la sensatez. (Prot. 332e11-12)

Tras obtener estas respuestas, Sócrates se dispone a cumplir con el tercer momento del élenchos, esto es, mostrar la inconsistencia entre las proposiciones dadas por el sofista:

16 Cf. Taylor, C.C.W., Notes on Plato's Protagoras, p.127. 
(12) “-¿Cuál de las dos respuestas, pues, Protágoras, abandonaremos? $¿$ La de que para cada cosa hay solo un contrario, o aquella en que se afirmaba que la sabiduria era distinta de la sensatez, y que cada una por su lado eran parte de la virtud, y diferentes entre sí y desemejantes ellas mismas y sus facultades, como las partes del rostro? ¿Cuál dejamos ahora? Ya que esas dos respuestas no se llevan muy armónicamente entre sí. Pues ni concuerdan ni encajan una con otra. Porque, ¿cómo van a acoplarse, si es necesario que para cada cosa haya solo un contrario y no más, y en cambio a la insensatez, que es una sola cosa, ahora le aparecen contrarias la sabiduria y la sensatez? ¿Es así, Protágoras, o de algún otro modo?

-Lo reconoció, aunque de muy mala gana" (Prot. 333a1-b3).

En este pasaje, Sócrates manifiesta la inconsistencia entre las afirmaciones de su interlocutor, producto del amplio sentido de la noción de "opuesto" (enantion). $q$ dice que la insensatez es opuesto polar de la sabiduria, mientras que $s$ dice que la insensatez y la sensatez son opuestos contradictorios. Este doble sentido está presente en la amplia noción de "opuesto" (enantion) presente en $r$. De este modo, nuevamente, reduce al absurdo la tesis del sofista.

Hemos visto, en el primer argumento, de qué manera el pronombre indefinido (tis), en su modalidad "anónima", era introducido dentro del segundo momento de la refutación (tomando como referencia la estructura de Benson). Alli pudo introducir los pares contradictorios (y no contrarios) asociados a cada virtud, de modo que logró conducir al sofista de un modo falaz hacia la refutación. Incluso, vimos que esta confusión entre pares "contradictorios" y "contrarios" perduró una vez que el anónimo desapareció de la conversación, y permitió que Sócrates, gracias a la amplitud semántica de la noción de "opuesto" (enantion), ponga en aprietos al sofista nuevamente.

El objetivo principal de introducir un interlocutor anónimo consistió en construir la figura de un otro (anónimo) para que Sócrates se pueda asociar a Protágoras y, así, responder en nombre de los dos. De este modo, llevando a cabo la "investigación conjunta", logró la "adquisición de ciertas premisas" y la "implicación indirecta del interlocutor"17. A propósito de esta última función, Longo dice lo siguiente: "En este tipo de situación y, en particular, en el contexto

\footnotetext{
${ }^{17}$ En su análisis sobre este primer momento refutativo, Beversluis advierte que el "tercer cuestionador" (third-party questioner) forma parte de una estrategia socrática para lograr el asentimiento de algunas tesis que luego recaerán sobre el sofista, al mismo tiempo que elude responsabilidad sobre las preguntas. $C f$. Beversluis, J., Cross-examining Socrates, pp. 264-265.
} 
de una refutación, el recurso a la interrogación ficticia y, sobre todo, a un interrogador anónimo (un tis), le permite a Sócrates disminuir sensiblemente la tensión interna del diálogo"18.

En el próximo apartado veremos la utilización del recurso del anonimato en otro élenchos del diálogo, donde Sócrates introducirá la voz de la mayoría para asociarse a Protágoras y conducir al sofista hacia la refutación.

\section{El anonimato de la mayoría en el último élenchos}

El último proceso refutativo del Protágoras tiene como protagonista a un tipo particular de interlocutor anónimo: la multitud (hoi pollot). No es ajeno a las muchedumbres el anonimato que la conglomeración de gente genera. Cuando habla la multitud, se asiste a un proceso de desindividualización, permitiendo que voces anónimas se alcen en nombre de todos y de nadie ${ }^{19}$. Si bien ciertos discursos atribuidos a "la mayoria" tienen fundamentos en la experiencia, puesto que corresponden a pensamientos extendidos en la cultura griega, especialmente, aquellos correspondientes al hedonismo circulante, es cierto que la manera en la cual se articulan dichos razonamientos dentro del contexto argumentativo corresponde a una manipulación de Sócrates con objetivos precisos.

En el argumento, la voz de la mayoría va a ser introducida por Sócrates con una finalidad puntual, esto es, asociarse a Protágoras, de modo que el sofista acepte proposiciones que luego irán en su contra (adquisición de ciertas premisas). Siguiendo el mismo modus operandi que en el caso anterior, Sócrates utilizará el recurso del anonimato para construir un "nosotros" con el sofista y, una vez logrado su objetivo, se ocupará de refutar a Protágoras sin la presencia del anónimo.

El primer paso de este proceso refutativo comienza cuando Sócrates retoma la tesis según la cual la sabiduria, la sensatez, el valor, la justicia y la piedad son partes de la virtud (349b1-6). En esta ocasión, Protágoras agrega que el valor se diferencia de las otras virtudes:

${ }^{18}$ Cf. Longo, A., L' art du questionnement et les interrogations fictives chez Platon, p. 157.

19 Los estudios sobre psicología de masas establecen un vínculo entre el anonimato y la pérdida de la individualidad en las multitudes. Cf. Le Bon, G., Psychologie des foules, Paris: Alcan, 1895. Durante el siglo XX, el desarrollo de las ciudades y la aparición de las masas en la escena pública fomentó el análisis de este fenómeno entre las ciencias sociales. Cf. Simmel, G., El individuo y la libertad. Ensayos de critica de la cultura, Barcelona: Península, 1986. Actualmente la discusión gira en torno a los "no-lugares" como espacios del anonimato. Cf. Augé, M., Los "no lugares". Espacios del anonimato, Barcelona: Gedisa, 1994. 
(13) “-Ahora te digo, Sócrates, afirmó, que todas esas son partes de la virtud; cuatro de ellas, muy cercanas entre sí, pero la quinta, el valor, difiere muy mucho de todas las demás. En lo siguiente conocerás que digo la verdad. Encontrarás, desde luego, a muchos hombres que son injustísimos, de lo más impío, de lo más intemperante y muy ignorantes, pero extraordinariamente valientes" (Prot. 349d2-8).

En esta oportunidad Protágoras parte desde la valentía para pensar la relación entre las virtudes, sugiriendo que es posible no ser justo, ni sabio, ni pío, pero sí ser valiente. Sócrates es elegido para conducir el análisis de dicha afirmación. Para ello, primero discutirá contra la mayoría y, luego, se ocupará directamente del sofista. Así como se examina a un hombre que va al médico (352a2-6), el filósofo le pide al sofista que muestre otras partes de su pensamiento para contraponerlo con la opinión de la mayoria:

(14) “Venga, por favor, ahora Protágoras, descúbreme este costado de tu pensamiento: ¿Qué opinas de la ciencia? ¿Es que tienes la misma opinión de la mayoría, o piensas de modo distinto?' La mayoría piensa de ella algo así como que no es firme ni conductora, ni soberana' (Prot. 352b1-3).

Sócrates le adjudica al vulgo la tesis: "la ciencia (episteme) es esclava de las pasiones" (352b8-c2); dicho de otro modo, el dolor, el amor, el miedo, y otros sentimientos someten al conocimiento y determinan las acciones de los hombres. Por su parte, Sócrates y Protágoras van a sostener la tesis opuesta, a saber, que el conocimiento (episteme) es soberano de los placeres ${ }^{20}$. Finalmente, haber defendido esto le costará caro a Protágoras, ya que algunas de las premisas que aceptará para destruir la posición de la mayoría formarán parte del argumento subsecuente sobre la valentía ${ }^{21}$.

La modalidad indirecta aparece en los primeros momentos del argumento, por ejemplo, cuando Sócrates dice: "Venga, pues, intenta persuadirlos conmigo y enseñarles en qué consiste esa experiencia que ellos califican como ser dominados por los placeres" (352e5-353a1). En vistas a aclarar el significado de esa expresión, Sócrates formula preguntas a la mayoria y Protágoras se ocupa de ratificar las respuestas socráticas con expresiones del tipo: "lo afirmarian"

${ }^{20}$ Cf. Gagarin, M., "The Purpose of Plato's Protagoras", en: Transactions and Proceedings of the American Philological Association, v. C (1969),pp. 133-164, p. 156.

${ }^{21}$ Cf. Woolf, R., "Consistency and Akrasia in Plato's "Protagoras", en: Phronesis, v. XLVII, n.13 (2002), p. 229. 
(353c8), o "el vulgo respondería así" (353e1-3). Veamos un ejemplo de este intercambio que se extenderá a lo largo de varios pasajes:

(15) "Y si nos preguntaran de nuevo: '¿Qué decís, entonces, que es eso que nosotros llamamos 'ser vencido por los placeres'?', yo les contestaría así: 'Atended. Intentaremos explicároslo Protágoras y yo. ¿Eso y no otra cosa creéis que es lo que os sucede en los casos que, muchas veces, subyugados por comidas o bebidas o atractivos sexuales, que os resultan placenteros, hacéis tales cosas aunque reconocéis que son perniciosas?'

-Lo afirmarian" (Prot. 356c1-7)

A partir de ahí comienza un diálogo con la mayoría que mantendrá al filósofo y al sofista unidos, especialmente entre los pasajes 353a3-358a1, donde el anonimato irá alternando la primera persona del plural ("nosotros", la mayoria), con usos del pronombre indefinido (tis) que expresará casos individuales dentro de la muchedumbre ${ }^{22}$. Esta variación no implica ninguna diferencia en el significado de las palabras anónimas, simplemente pone al servicio de la conducción del diálogo ambos modos de ser anónimo:

(16) "Entonces consideráis que el mal es el dolor; y el bien, el placer. Ya que también al mismo tiempo gozar lo llamáis malo en aquella ocasión en que os priva de mayores placeres de los que él aporta, u os causa mayores dolores que los placeres que hay en él. Porque si, según otra razón llamarais malo al gozar y atendierais a otro objetivo, podriais sin dudas decírnoslo. Pero no podréis" (Prot. 354c5-7).

Taylor encuentra que en este pasaje Sócrates le atribuye a la masa la tesis del "hedonismo evaluativo", según la cual algo es bueno sí y solo sí es placentero, y es malo sí y solo sí carece de placer ${ }^{23}$. Esta será una de las premisas que jugarán un rol especial en el argumento contra el sofista. Es necesario mencionar que la conversación con la mayoría se origina en vistas a examinar si resulta ser lo mismo lo bueno y lo placentero (351e5), y Protágoras se compromete a aceptarla si el razonamiento así lo sugiere. Esta premisa luego será admitida por todos en 358b1-3.

A lo largo de la conversación con la mayoria, Sócrates conduce a los anónimos a aceptar cuatro tesis que llevarán a contradicción:

\footnotetext{
${ }^{22}$ Taylor en su análisis de este pasaje llama al interlocutor anónimo: "hombre común" (common men).

${ }^{23}$ Cf. Taylor, C.C.W., Notes on Plato's Protagoras, p. 175
} 
i) El placer del momento aventaja al dolor del futuro (356a5-7)

ii) La felicidad consiste en esto: en hacer y escoger los mayores tamaños, y en evitar y renunciar a los más pequeños ("¿qué se nos mostraría como la mejor garantía de nuestra conducta? ¿Acaso el arte de medir, o acaso el impacto de las apariencias?..." (356c8-d4)).

iii) "Bueno, señores. Ya que nos pareció que la salvaguarda de la vida consistía en la recta elección del placer y del dolor, del mayor y el menor, del más numeroso y el que menos, tanto de más lejos como de más cerca. ¿no os parece una métrica, en principio, el examen de la superioridad y la inferioridad o la igualdad de uno y otro?" (357a5-b3).

iv) "Puesto que es métrica, seguro que será un arte y una ciencia (episteme)" (357b4).

De estas cuatro tesis se deduce que la ciencia domina al placer (357c2-3), contradiciendo así la opinión del vulgo, según la cual los placeres dominan al hombre y a su conocimiento. Esta refutación le permite al filósofo abandonar la figura de la mayoría para continuar con el proceso refutativo directamente contra el sofista.

En este nuevo escenario, Socrates tiene algunos elementos que le van a permitir contradecir la tesis de Protágoras acerca de la diferencia entre el conocimiento y la valentía. Una de las premisas que estarán en juego será producto de la asociación entre el sofista y Sócrates contra la mayoría, me refiero a la aceptación implícita de Protágoras sobre la identificación entre el bien y el placer, que es confirmada por Pródico y todos los demás (incluyendo a Protágoras ${ }^{24}$. En 358a5-6 los sofistas se declaran a favor de que lo placentero es bueno. Taylor sostiene que la intervención del anónimo pudo haber producido un cambio en la mente de Protágoras, debido a que el sofista no logra distinguir entre las afirmaciones de Sócrates y aquellas del "hombre común"25. En esta línea nosotros afirmamos que estamos en presencia de uno de los efectos que produce el recurso del anonimato, me refiero a la "implicación indirecta del interlocutor". Más que una confusión, nosotros interpretamos que el sofista es víctima de una táctica psicológica manipulativa que lo llevó a afirmar:

${ }^{24}$ Cf. Kahn, C.H., Plato and The Socratic Dialogue, Cambridge: Cambridge University Press, 1996, p. 236; Woolf, R., "Consistency and Akrasia in Plato's Protagoras", en: Phronesis, XLVII (2002), pp. 224-252, p. 229.

${ }^{25}$ Cf. Taylor, C.C.W., Notes on Plato's Protagoras, p. 201. 
i) La ciencia es soberana de las costumbres humanas.

ii) Las cosas placenteras son buenas.

A partir de 358d1 se descarta la posibilidad de que los hombres vayan hacia los males, sino más bien todo lo contrario, y se introduce la noción de "miedo", asociada al mal. Nadie va a dirigirse hacia lo que cree temible. De ese modo, el argumento buscará distinguir al valiente y al temeroso en función de la presencia o ausencia de conocimiento. La conversación entre Sócrates y los sofistas continúa con la afirmación de las siguientes premisas:

iii) Ir a la guerra es hermoso, bueno y placentero (360a3).

iv) Los cobardes son cobardes por ignorancia (360c6).

v) El valor es contrario a la ignorancia(360d5).

De estas premisas se deduce que es imposible que haya hombres ignorantes y valientes ya que, según lo que se dijo, los hombres son valerosos por el conocimiento. Así, Protágoras se contradice con su afirmación sobre las partes de la virtud que citamos al comienzo de este apartado. En (13) Protágoras había afirmado que hay hombres ignorantes pero extremadamente valientes, algo que resulta inconsistente con lo que se deduce de las proposiciones aceptadas.

Esta reconstrucción del último élenchos del Protágoras nos permite dar cuenta de la funcionalidad del anónimo dentro del proceso refutativo. El uso de este dispositivo permitió que Protágoras acepte dos premisas claves para su derrumbe. La habilidad de Sócrates para conducir los argumentos reposa, por momentos, en su capacidad para introducir voces anónimas, y de este modo asociarse a su interlocutor. La investigación conjunta, al tener un oponente en común, facilita que el interlocutor acepte las tesis socráticas.

\section{El uso del anonimato en el primer élenchos del Gorgias}

Al igual que en el Protágoras, la figura del interlocutor anónimo está intimamente relacionada con la capacidad de Sócrates para conducir los diálogos. Además de usar al anónimo con el objetivo de lograr que el sofista 250 asiente proposiciones que luego irán en su contra, encontramos en este diálogo una función que Longo llama "paradigmática", por medio de la cual Sócrates ejemplifica el modo en que espera obtener las respuestas de Gorgias ${ }^{26}$ :

${ }^{26}$ Longo, A., L'art du questionnement et les interrogations fictives chez Platon, p. 155. 
(17) "Sóc.- ...Por ejemplo, si sobre alguna de las artes de que ahora hablaba, alguien (tis) me preguntara: 'Sócrates, ¿qué es la aritmética?', le contestaría, como tú ahora, que es una de las artes que produce su eficacia por medio de la palabra. Si, continuando la pregunta, me dijera: ‘¿Sobre qué objeto?’, le contestaría que sobre lo par y lo impar y la cantidad de cada uno. Si nuevamente me preguntara: ‘Qué es el cálculo?', le diría que también es una de las artes que tienen toda su eficacia en la palabra, y si insistiera: ‘¿Sobre qué objeto?', le respondería, como los que redactan las propuestas en la asamblea..." (Gorg. 451a7-b7) ${ }^{27}$.

La función paradigmática le permite a Sócrates ejemplificar el tipo de respuesta que espera de su interlocutor. En este caso, el anónimo interroga al filósofo sobre diferentes artes y sus respetivos objetos, y Sócrates va respondiendo, tal como espera que lo haga Gorgias. La posibilidad de utilizar un anónimo le permite a Sócrates ponerse en el lugar de quien responde, sugiriendo que su interlocutor continúe el modelo de respuesta. Es importante tener presente que en 449d1-2, Sócrates ya formuló la pregunta sobre la retórica y su objeto de conocimiento, de modo tal que en el pasaje citado le enseña a Gorgias cómo debería responder a esa pregunta.

Llama la atención que el anónimo le pregunte a Sócrates exactamente lo mismo que este le preguntó a Gorgias. Las semejanzas entre las preguntas del filósofo y las del anónimo sugieren que por detrás de la condición anónima se esconde la figura de Sócrates. Ahora bien, al adjudicarle los razonamientos a otro personaje, y darle voz dentro el diálogo, los interlocutores actúan como si el anónimo fuera alguien diferente de Sócrates. Esto mismo se percibe cuando el filósofo trae a la presencia la voz de un maestro de gimnasia, o un médico. Si bien la profesión da signos leves de una identidad, la modalidad en la que se presentan estos personajes sin nombre, y el uso que se les da, corresponde exactamente con los casos investigados ya que, como hemos mencionado, es el filósofo que hace como si fuera otra persona y se oculta tras la máscara de un profesional:

(18) "Sóc.- Porque si, por ejemplo, estuvieran delante de ti los que profesan las artes que alabó el autor del escolio: el médico, el maestro de gimnasia y el banquero, y, en primer lugar, dijera el médico: 'Sócrates, Gorgias te engaña; no es su arte el que procura el mayor

\footnotetext{
27 Para todos los pasajes del Gorgias seguimos la traducción de Ruiz Calonge. Cf. Platón, Diálogos II. Gorgias, Menéxeno, Eutidemo, Menón, Crátilo, Ruiz Calonge, J. (trad.), Madrid: Gredos, 1999.
} 
bien a los hombres, sino el mío', y yo le preguntara: ‘¿Qué eres tú, para expresarte así?', contestaría probablemente que médico. ‘¿ué dices? ¿El producto de tu arte es el mayor bien?', ‘CCómo no, Sócrates?', diría quizás. '¿Hay algún bien mayor para el hombre que la salud?' Si después de este, el maestro de gimnasia dijera: 'También a mí me causaría sorpresa, Sócrates, que Gorgias pudiera demostrarte que su arte produce un bien mayor que el mío'; igualmente le preguntaría yo a éste: '¿Qué eres, amigo, y qué obra realizas', 'Maestro de gimnasia, diría, y mi obra consiste en dar a los cuerpos fuerza y belleza'... 'Pues aquí tienes a Gorgias que afirma, contra lo que tú dices, que su arte es causa de un bien mayor que el tuyo'. Es evidente que después de tal afirmación él preguntaria: ‘¿Qué bien es ese? Que conteste Gorgias'. Pues bien, Gorgias, piensa que ellos y yo te hacemos esta pregunta y contéstanos: ¿Cuál es ese bien que, según dices, es el mayor para los hombres y del que tú eres artífice? (Gorg.452a-d).

Este pasaje nos pone en contacto con otros modos de ser anónimo. No siempre la máscara será la misma, sino que puede variar y, si es necesario, adoptar la forma de un profesional anónimo. Recordemos que venimos considerando "interlocutor anónimo" como aquel "alguien" (tis) cuya presencia Sócrates se ocupa de introducir en el diálogo, o a la voz de la mayoria (hoi pollot). De todas maneras, el pasaje citado nos sirve para problematizar un caso extremo, en el cual Sócrates adopta las palabras de un banquero, un médico y un maestro de gimnasia. Si bien se describe a la persona según su profesión, nada impide que la adopción de máscaras esconda la identidad del filósofo. El modo en que es introducido el anónimo por Sócrates, y la función dentro del diálogo responden al mismo registro que venimos investigando, incluso mantienen el modo dialéctico de conducirse, formulando preguntas y respondiendo a su turno. Sin dudas, es él mismo quien se desdobla (para utilizar las palabras de Appel) y adopta las palabras de un supuesto banquero. Sin embargo, a los ojos de los dialogantes, parece realmente un profesional que toma la escena ${ }^{28}$.

El comienzo del primer élenchos del diálogo se demora en llegar por la necesidad que tiene Sócrates de determinar con precisión el objeto de la retórica. Precisamente, luego de utilizar el recurso del anonimato en modo "paradigmático", el filósofo vuelve a realizar la pregunta por el objeto, pero esta vez

\footnotetext{
${ }^{28}$ Apelt analizó el tema de la duplicaión y escisión (Spaltung und Verdoppelung) como parte de la estrategia socrática para conducir los diálogos. Cf. Apel, O., Platonische Aufsatze, Leipzig: Teubner, 1912, pp. 96ss.
} 
se la hace al personaje imaginario y espera que la responda Gorgias: “¿Qué persuasión produce la retórica y sobre qué objeto?” (454a8-9). Gracias a que Sócrates ya ejemplificó cómo debía responder, Gorgias contesta que se trata de la persuasión que se produce en los tribunales y otras asambleas sobre lo justo y lo injusto (454b5-7). A partir de esta respuesta se va a desplegar el primer élenchos del diálogo. El primer paso será distinguir entre conocimiento (máthesis) y creencia (pístis). Precisamente, la siguiente pregunta anónima será sobre la distinción entre creencia falsa y creencia verdadera: "Sóc.- Si te preguntaran: ‘¿Hay una creencia falsa y otra verdadera, Gorgias?', contestarias afirmativamente, creo yo" (Gorg. 454d4-6).

No es casualidad que esta pregunta sea introducida indirectamente, ya que si tenemos en cuenta al Gorgias histórico, este interrogante no es tan sencillo de responder. Recordemos que en el tratado Sobre el no ser, Sexto Empírico concluía que, para el sofista, el criterio de verdad desaparece ${ }^{29}$. La imposibilidad de poder comunicar al ser hacía imposible toda verdad. De ese modo, no habria una diferencia entre creencia verdadera y creencia falsa, tal como sugiere Sócrates ${ }^{30}$. Sin embargo, en el Encomio de Helena o Palamedes, se supone que hay una diferencia entre la verdad y aquello que se le opone ${ }^{31}$. Esta distinción nos da la pauta de que, evidentemente, Gorgias pudo haber problematizado la tesis según la cual hay creencias verdaderas y creencias falsas. Estos datos que provienen de los estudios sobre los sofistas nos permiten comprender la importancia que tiene dentro del élenchos formular una pregunta problemática de modo indirecto, dado que le facilita al filósofo responder por Gorgias, y así evitar una complicación en la conducción de la argumentación (función de implicación indirecta). De esta manera, saltea la dificultad que supone el hecho de habilitar al sofista a desarrollar una respuesta.

\footnotetext{
29 Teniendo en cuenta la segunda tesis del tratado SNS, Gorgias afirma que "lo que es no es pensado" (SNS 78). Siguiendo una concepción correspondentista de la verdad, Untersteiner concluye que todo lo pensado es falso (tragedia gnoseológica). Cf. Untersteiner, M., Les Sophistes, Paris: Vrin, 1993, pp. 160ss.

${ }^{30} C f$., entre otros, Spangerberg, P., "Persuasión y apáte en Gorgias", en: HYPNOS, v. XXIV (2010), pp. 69-92, p. 69; Gigon, O., "Über das Nichtsein”, en: Hermes, v. LXXI (1936), pp. 186-213, p.206; y Kerferd, G.B., "Gorgias on Nature of that Which Is Not", en Phronesis, v. I (1955), pp. 3-25, p. 24. 31 Cf. Porter, J.I., “The Seductions of Gorgias”, en: Classical Antiquity. XXII (1993), pp. 267-299, p. 292; Valiavitcharska, V., "Correct Logos and Truth in Gorgias' Encomium of Helen", en: $A$ Journal of the History of Rhetoric, v. XXIV (2006), pp. 147-161, p. 153. Es interesante también la tesis de Cassin, según la cual, los discursos persuasivos son verdaderos porque producen su propio objeto, en el sentido de que el ser es efecto del decir. Cf. Cassin, B., L'effet sophistique, Paris: Gallimard, 1995, pp. 11-15.
} 
Siguiendo con la estrategia socrática, el filósofo distingue entre dos tipos de persuasión: aquella que, por medio de la enseñanza, transmite el saber, y la que transmite la creencia sin saber. Del lado de esta última está la retórica, artífice de la persuasión que da lugar a la creencia, pero no a la enseñanza sobre lo justo y lo injusto. Esto es afirmado por Gorgias y ambos dejan en claro que no le corresponde a la retórica lo relativo a la enseñanza de lo justo. Una vez alcanzada esta afirmación, el objetivo de Sócrates será conducir al sofista a que afirme proposiciones que contradigan esto. Para ello, el filósofo introduce la voz de un interlocutor anónimo que se presenta bajo la forma de "posibles discípulos":

(19) "Sóc.-... Así pues, considera, al ser preguntado por mí, que son también ellos los que te preguntan: ¿¿Qué provecho obtendremos, Gorgias, si seguimos tus lecciones? ¿Sobre qué asuntos seremos capaces de aconsejar a la ciudad? ¿Solo sobre lo justo y lo injusto o también sobre lo que ahora decía Sócrates?' Así pues, procura darles una contestación" (Gorg. 455d2-4).

A partir de este momento, Sócrates comienza a sentar las bases del derrumbe del sofista. La clave de la estrategia socrática es poner en escena a los posibles discípulos. ¿Acaso un vendedor va a decirle que no a un posible cliente? Es claro que el sofista contestaría positivamente ante cualquier pregunta sobre las capacidades de sus servicios. Ser capaz de aconsejar a la ciudad sobre lo justo y lo injusto no es lo mismo que persuadir sobre ello. Lentamente, el filósofo va logrando su cometido. Una vez puestos en escena los futuros clientes, el interlocutor anónimo no vuelve a aparecer; solo resta que Sócrates continúe con el plan ${ }^{32}$.

La conversación transcurre, y Gorgias expone la potencia de la retórica, dando cuenta de la capacidad de influir con mayor éxito que un médico ante un enfermo que se niega a tomar su medicina. Ahora bien, nos dice que es preciso utilizar a la retórica del mismo modo que los medios de combate, no por saberlos usar hay que emplearlos contra todo el mundo, sino que es justo utilizar las armas contra los enemigos y no contra los amigos (456d3-5). De todos modos, el sofista deja abierta la posibilidad de que el alumno actúe injustamente, cuando

\footnotetext{
${ }^{32}$ Más adelante en el diálogo, Calicles considerará a este pasaje como fundamental en la contradicción de Gorgias, argumentando que el sofista aceptó enseñarle sobre la justicia a un discípulo (en caso de que pretenda aprender retórica sin conocer qué es lo justo), por verguenza a decir que no, "a causa de la costumbre de los hombres, que se indignarian si alguien dijera que no puede enseñar qué es lo justo". $C f$. 482d2-3.
} 
dice: "si alguien adquiere habilidad en la oratoria y, aprovechando la potencia de este arte, obra injustamente, no por ello se debe odiar ni desterrar al que le instruyó" (457b5-7). Con estos comentarios el sofista quiere deslindarse de la responsabilidad ante un alumno que proceda injustamente. Precisamente, estas aclaraciones le costarán caro:

(20) "Sóc.- No sigas; tu contestación es suficiente. Si has de hacer orador a alguien, es preciso que conozca lo justo y lo injusto, bien lo sepa antes de recibir tus lecciones o bien lo aprenda contigo. Gorg.Exactamente" (Gorg. 460a5-7).

A partir de ese momento, siguiendo a Kahn, "Gorgias entró en la trampa"33, y el argumento continúa del siguiente modo (460b-c):

(a) Si has de hacer orador a alguien es preciso que conozca lo justo y lo injusto, o lo aprenda contigo (460a5-7).

(b) Si el estudiante aprende sobre lo justo, actuará justamente (460b8).

(c) El orador no querrá hacer un uso injusto de la retórica (460c5-6).

Ahora bien, Gorgias aceptó previamente la posibilidad de que el alumno use la retórica de un modo injusto, en tal caso no habria que acusar al maestro, ya que este le había enseñado a usar la retórica justamente. Esta contradicción termina con la refutación de Gorgias, y da lugar a la aparición de Polo, quien será objeto de un nuevo élenchos.

En esta refutación, el anónimo fue introducido con dos objetivos. Por un lado, como vimos al comienzo, Sócrates ejemplifica por medio del anónimo el modo en que Gorgias debe responder a la pregunta por el objeto de la retórica ${ }^{34}$. Por otro lado, el recurso del anónimo le permite a Sócrates llevar el diálogo hacia lugares a los que de otro modo seria dificil llegar; por ejemplo, cuando Sócrates adopta la forma de los discípulos interesados en aprender retórica, y formula la pregunta sobre los beneficios de seguir las lecciones, entre esos beneficios incluye lo justo y lo injusto.

\footnotetext{
${ }^{33}$ Kahn, C., Plato and The Socratic Dialogue, p. 65.

34 En Fedón 105b5-c5 encontramos la misma estrategia: Sócrates insta a su interlocutor a que lo imite, y expone el tipo de respuesta que espera obtener.
} 


\section{Conclusión}

La reconstrucción del contexto argumentativo donde aparece un interlocutor anónimo en los diálogos Protágoras y Gorgias, ya sea por medio del pronombre indefinido (tis), la figura de la mayoría (hoi polloi), o bajo la máscara de alguna profesión (el médico, el banquero, etc.), nos permitió identificar las funciones que la autora Angela Longo le adjudica a las interrogaciones ficticias que incorporan una voz anónima. Hemos visto que las funciones de "implicación indirecta del interlocutor" y "adquisición de ciertas premisas" tienen lugar en el segundo momento del élenchos, tomando como referencia a la estructura de Benson. Sin embargo, la función "paradigmática" se presenta antes de que comience el proceso refutativo. Así lo indica la introducción del Gorgias (pasajes 17 y 18), e incluso también la del Protágoras (pasajes 1, 2 y 3), citados al comienzo del trabajo.

El hecho de que el pronombre indefinido (tis) sea presentado como una tercera voz en la refutación hace que el interlocutor no lo interprete como un mero desdoblamiento del filósofo, sino que lo tome como un verdadero interlocutor ficticio que se incorpora a la conversación, permitiéndole a Sócrates asociarse a Protágoras o Gorgias. De ese modo, el filósofo construye un "nosotros" que se opone a la figura anónima. Esto tiene consecuencias persuasivas que se condicen con lo que Beversluis llama "psychologically manipulative tactics", es decir, tácticas psicológicas persuasivas, que conducen al interlocutor a aceptar tesis ${ }^{35}$.

Recibido: 07/09/2015

Aceptado: 28/09/2016

${ }^{35}$ Cf. Beversluis, J. o.c., p.46. 


\section{Bibliografia}

Apelt, O., Platonische Aufsatze, Leipzig: Teubner, 1912.

Augé, M., Los “no lugares”. Espacios del anonimato, Barcelona: Gedisa, 1994.

Benson, H.H., "The Problem of the Elenchus Reconsidered", en: Prior, W. (ed.), Critical Assessment (Vol. III: Socratic Method), Nueva York: Routledge, 1987, pp. 97-118. https://doi.org/10.5840/ancientphil198776

Benson, H.H., "Problems with Socratic Method", en: Alan Scott, G. (ed.), Does Socrates have a Method? Rethinking the Elenchus in Plato`s Dialogues and Beyond, Pensilvania: The Pennsylvania State University Press, 2002, pp.101-113.

Beversluis, J., Cross-examining Socrates, Cambridge: Cambridge University Press, 2000. Brickhouse, C. y N. Smith, "Socrates and the Unity of the Virtues", en: The Journal of Ethics, v. I, 4 (1997), pp. 311-324. https://doi.org/10.1023/A:1009710215472

Cassin, B., L'effet sophistique, Paris: Gallimard, 1995.

Cornford, F.M., "The Athenian Philosophical Schools", en: Cambridge Ancient History, v. VI (1927), pp. 310-332.

Desclos, M.L., "L’interlocuteur anonyme dans les dialogues de Platon", en: Cossutta, N. (ed.), La forme dialogue chez Platon. Évolution et réceptions, Grenoble: Jérôme Million, 2001, pp. 69-97.

Devereux, D., "The Unity of the Virtues", en: The Philosophical Review, v. CII (1993), pp. 765-789.

Di Camillo, S., Eidos. Teoría platónica de las Ideas, La Plata: Edulp, 2016.

Gagarin, M., "The Purpose of Plato's Protagoras", en: Transactions and Proceedings of the American Philological Association, v. C (1969), pp. 133-164.

Gigon, O., "Über das Nichtsein”, en: Hermes, v. LXXI (1936), pp. 186-213.

Goodell, T.D., "Plato's Hedonism", en: The American Journal of Philology, v. XLII (1921), pp. 25-39. https://doi.org/10.2307/289396

Hackfort, R., "Hedonism in Plato's Protagoras", en: Classical Quarterly, v. XXII (1928), pp. 39-42.

Irwin, T.H., "Say What You Believe", en: Apeiron, v. XXVI, (1993), pp. 1-16. https://doi. org/10.1515/APEIRON.1993.26.3-4.1

Kahn, C.H., Plato and The Socratic Dialogue, Cambridge: Cambridge University Press, 1996.

Kerferd, G.B., "Gorgias on Nature of that wich is not", en: Phronesis , v. I, 1 (1955), pp. 3-25. https://doi.org/10.1163/156852855X00023

Le Bon, G., Psychologie des foules, Paris: Alcan, 1895.

Longo, A., L' art du questionnement et les interrogations fictives chez Platon, Lernould, A. (trad.), Milán: Mimesis Edizioni, 2007. Versión original: La tecnica della domanda e le interrogazioni fittizie in Platone, Pisa: Scuola Normale Superiore, 2000.

Lyons, J., Semantics, Londres: Cambridge University Press, 1993.

Penner, T., "The Unity of Virtue", en: Philosophical Review, v. LXXXIII (1973), pp. 35-68. https: / / doi.org/ 10.2307/2184238 
Platón, Diálogos II. Gorgias, Menéxeno, Eutidemo, Menón, Crátilo, Ruiz Calonge, J. (trad.), Madrid: Gredos, 1999.

Platón, Diálogos I: Apología, Critón, Eutifrón, Ion, Lisis, Cármides, Hipias Menor, Hipias Mayor, Laques, Protágoras, Garcia Gual, C. (trad.), Madrid: Gredos, 2000.

Porter, J.I., "The Seductions of Gorgias", en: Classical Antiquity, v. XXII (1993), pp. $267-$ 299. https://doi.org/10.2307/25010996

Simmel, G., El individuo y la libertad. Ensayos de critica de la cultura, Barcelona: Península, 1986.

Spangerberg, P., "Persuasión y apáte en Gorgias”, en: HYPNOS, v. XXIV (2010), pp. 69-92.

Sullivan, J.P., "The Hedonism in Plato`s Protagoras" en: Phronesis, v. VI (1961), pp. 10-28. https://doi.org/10.1163/156852861X00026

Taylor, C.C.W., Notes on Plato's Protagoras, Oxford: Clarendon Press, 2002 (edición revisada del original de 1976).

Valiavitcharska, V., "Correct Logos and Truth in Gorgias' Encomium of Helen", en: A Journal of the History of Rhetoric, v. XXIV (2006), pp. 147-161.

Vlastos, G., "The Unity of the Virtues in the Protagoras", en: Vlastos, G., Platonic Studies, Princeton: Princeton University Press, 1981 (2 ed.), pp. 418-423.

Vlastos, G., "The Socratic Elenchus", en: Fine, G. (ed.), Plato 2. Ethics, Politics, Religion and the Soul, Oxford: Oxford University Press, 1999, pp. 36-63.

Woolf, R., "Consistency and Akrasia in Plato's Protagoras", en: Phronesis, v. XLVII (2002), pp. 224-252. https://doi.org/10.1163/15685280260458136 